\title{
Limitations to Signaling Trust with All or Nothing Investments
}

\author{
Eric Schniter ${ }^{a}$ \\ Roman M. Sheremeta ${ }^{b}$ \\ Timothy W. Shields ${ }^{\mathrm{c}, *}$ \\ ${ }^{a}$ Economic Science Institute, Chapman University \\ One University Drive, Orange, CA 92866, U.S.A. \\ ${ }^{\mathrm{b}}$ Department of Economics, Weatherhead School of Management, \\ Case Western Reserve University and the Economic Science Institute, \\ 11119 Bellflower Road, Cleveland, OH 44106, U.S.A. \\ ${ }^{c}$ Argyros School of Business and Economics, Chapman University, \\ One University Drive, Orange, CA 92866, U.S.A.
}

8 October 2013

\begin{abstract}
Many economic interactions are characterized by "all or nothing" action spaces that may limit a demonstrable index of trust and, therefore, the propensity to reciprocate. In two experimental trust games, the action space governing investments was manipulated to examine the effects on investments and reciprocity. In the continuous game the investor could invest any amount between $\$ 0$ and $\$ 10$, while in the binary game the investor could invest either $\$ 0$ or $\$ 10$. In both games, the trustee received the tripled investment and then could return any amount back to the investor. Investors invested significantly more in the binary game than in the continuous game. However, higher investments in the binary game did not lead to more reciprocity. To the contrary, conditional on investment of $\$ 10$, on average trustees returned significantly less in the binary game than in the continuous game.
\end{abstract}

JEL Classifications: C72, C91

Keywords: trust game, signaling, demonstrable index of trust, reciprocity, experiments

* Corresponding author: Timothy W. Shields (shields@chapman.edu) 1.714.289.2092 


\section{Introduction}

Trust and trustworthiness are fundamental to an efficient economy, where (i) trust is demonstrated by willfully ceding resources or control to another with the expectation that the other intends to reciprocate and not be opportunistic, and (ii) trustworthiness is demonstrated by not succumbing to opportunism so as to restitute the resources or control that another has ceded by extending trust. Interactions that require trust involve a basic social dilemma where agents have to trade off self-interest and safety with the potential benefits that arise from trusting and reciprocal behavior.

Prior research on trust/investment games has shown that the more a first mover (investor) demonstrates trust by voluntarily investing his endowment, the more likely the second mover (trustee) is to demonstrate trustworthiness by voluntarily returning discretionary income generated by the first mover's investment (Bacharach, Guerra \& Zizzo 2007; Reuben, Sapienza \& Zingales 2009). Ostrom and Walker (2003) reviewed continuous trust games (modeled after Berg, Dickhaut \& McCabe 1995), and found that larger amounts tend to generate positive returns on investment. Falk and Gächter, (2002) and Fehr, Gächter and Kirchsteiger (1996) found similar results in gift exchange games.

Given these results, we were motivated to explore whether truncating potential investors' action space (e.g., by giving only all or nothing options) would lead to a greater proportion showing "maximal trust". Eckel and Wilson (2004) studied trust games where investors could go all-in (investing their entire endowment) or all-out (keeping their entire endowment) and found that 80 percent of investors sent the full amount. If, as had been seen in previous studies, maximal trust was predictive of high levels of trustworthiness, could we not influence greater trustworthiness by imposing a restricted action space on potential trustors? 
We found this question about the efficacy of restricting action space most interesting because, although the suggested hypothesis is compelling, other research suggests that the relationship between trust and trustworthiness may not be so straightforward. Glaeser, Liabson, Schenikman and Soutter (2000) examined behavior in binary trust games and found that reciprocity is positively affected by perceived social closeness and investor's status. Bacharach, Guerra and Zizzo (2007) altered payoff structures in binary trust games and found evidence that perception of the investor's underlying sacrifice does alter reciprocity. Dufwenberg and Kirchsteiger (2004) analytically modeled reciprocity as increasing in the perception of the underlying investor's investment relative to what could have been done. That is, the trustee's perception of trust depends not only on what amount was invested, but also what alternative options to that investment had been available to the investor. We argue that the perception of one's degree of trust depends upon the granularity of the action space: in addition to what was demonstrated, the number of alternative behaviors that could have been demonstrated. An action space can affect the demonstration of trust, by revealing that the investor has forgone available alternatives, providing the trustee a demonstrable index of trust. A demonstrable index of trust with finer granularity should provide greater signaling fidelity and be better suited to overcoming motivational ambiguities which we explain in greater detail below. On the other hand, an index of trust with coarser granularity (such as the binary "all or nothing" option) is more ambiguous in what it can demonstrate.

To examine this supposition, we examined behavior in two experimental games. In the Continuous game, similar to Berg et al. (1995), the investor could invest any amount between $\$ 0$ and $\$ 10$, while in the Binary game the investor could invest either $\$ 0$ or $\$ 10$. In both games, the trustee who received the tripled amount of the investment could return any amount back to the 
investor. Our testable hypotheses were generated by a model in which agents' initial propensity to trust and be trustworthy is heterogeneous and affected by psychological costs. Investors are jointly motivated to demonstrate trust and to maximize earnings. Likewise, trustees consider their motivation to maximize earnings and motivation to demonstrate trustworthiness by reciprocating. This motivation towards trustworthiness is affect by evaluation of whether the investor's actions are evidence of motivation to demonstrate trust. The inference trustees can make about an investor's motivation to trust is more accurate (and provides greater confidence) when the granularity of the action space is finer. The model predicts that: (i) when the investment space is continuous, trustees are responsive to the demonstrable trust such that both the amount returned and return on investment are increasing in the amount invested; (ii) when the investment space is limited to a binary option, the amount sent increases, and as a result there is more pooling of investors with different propensity to trust; (iii) conditional on investing the maximum value, return on investment is lower when the investment space is binary than when it is continuous.

The experimental results are consistent with the model's predictions. Investors invested significantly more in the Binary game than in the Continuous game (\$7.71 versus $\$ 5.50)$. However, where the demonstrable index of trust is of coarser granularity, trustworthiness decreased. On average trustees who received $\$ 30$ income (from $\$ 10$ investment) returned significantly less in the Binary game than in the Continuous game (\$10.03 versus $\$ 12.71)$. These results suggest that although amounts invested have signal value indexing trust, binary action space limits this demonstrable index of trust, diminishing signal value. 


\section{Experimental Design and Procedures}

Two treatments were studied to examine how limiting the action space of an investor affects investment and subsequent reciprocity. The Continuous treatment was similar to Berg et al. (1995) where the investor received \$10 endowment and then decided to invest any amount (an increment of $\$ 0.01$ ) between $\$ 0$ and $\$ 10$. The trustee received three times the amount invested and then decided how much to return (any increment of \$0.01). The Binary treatment was similar to Dufwenberg and Gneezy (2000) where the investor received \$10 endowment and then decided to invest either $\$ 0$ or $\$ 10$ (i.e., "all or nothing”). As in the Continuous treatment, the trustee decided how much of the tripled investment to return (any increment of \$0.01).

The experiment was conducted at Chapman University's Economic Science Institute (ESI). A total of 248 participants were recruited from a standard participant pool consisting primarily of undergraduate students and randomly assigned into one of the two treatments. Those who had participated in trust-based experiments at ESI were excluded. Participants were seated at visually isolated work stations and interacted with each other anonymously over a local computer network. The experiment was programmed and conducted using z-Tree (Fischbacher, 2007).

Each of eleven sessions consisted of 18 to 24 participants, lasted approximately 35 minutes, and was sequenced as follows. First, an experimenter read the instructions aloud while each participant followed along with their own copy of the instructions. The instructions explained the experimental procedures and payoffs used in the experiment (instructions are available in the Appendix). After finishing the instructions, participants were given five minutes to write down their answers to several questions to ensure that they understood the instructions. Participants' answers remained confidential. After participants completed the quiz, the 
experimenter distributed a printed copy of the correct quiz answers. The experimenter privately answered any questions regarding the experimental procedures.

The computer randomly assigned participants into pairs and each participant within a pair was randomly assigned a role, labeled person 1 for the investor and person 2 for the trustee. Each participant was paid a $\$ 7$ participation fee and the payoffs from the trust game after signing a receipt. On average subjects earned $\$ 9.75$ in addition to their participation fee.

\section{Model and Hypotheses}

A simple theoretical model derived from Hotelling's (1929) location model is used to provide testable hypotheses. ${ }^{1}$ Assume that investors and trustees in the trust game hold two exclusive goals that are traded off yielding an amount invested $(s)$ out of the endowment $(e)$ for the investor, and an amount returned $(r)$ out of tripled amount received $(3 \mathrm{~s})$ for the trustee. Let $i$ index investors and $j$ trustees. Without loss of generality, payoffs and costs in the utility are normalized (by $e$ and $3 s$, respectively). The expected utility function of the investor $i$ is given by:

$$
W_{i}(s)=1-\alpha_{i} f\left(\frac{e-s}{e}\right)-f\left(\frac{s}{e}\right)+\frac{1+\alpha_{i}}{e} \mathbb{E}(r)
$$

The expected return from investment is $\mathbb{E}(r)$. The function $f(x)=x^{2}$ represents the psychological cost of taking an action different from the boundary condition (i.e., keep everything or invest everything). Investors incur a cost by keeping their endowment, interpreted

\footnotetext{
${ }^{1}$ Our model is also similar to Gómez-Miñambres and Schniter's (2013) model of self-control in intertemporal consumption choices, where emotional components of the utility function influence tradeoffs between two conflicting goals. In contrast, our model examines the strategic interactions of two agents in a sequential one-time interaction. Aside from the role of expectations about other agents, the costs imposed by negative emotions in Gómez-Miñambres and Schniter's model are analogous to the emotional costs of our one-parameter model of strategic behavior.
} 
as guilt, which stems from not pursuing a cooperative relationship with and/or showing regard for improving the welfare of the trustee. At the same time, investors incur a cost by sending their endowment, interpreted as insecurity, which derives from the increased sense of vulnerability brought on by ceded control of resources. The relative difference in these emotional costs is captured by the weight $\alpha_{i}$, representing the investor's predisposition to cooperation, where $\alpha_{i}$ is drawn from a distribution characterized by a distribution function $q(\alpha)$. An interpretation is that when the value is low, the investor is more motivated by securing immediate and certain material gains, and when the value is high, the investor is more motivated by developing a cooperative relationship. When $\alpha_{i}=0$, the investor is driven primarily by the expected return from cooperation, and the amount invested $(s)$ is determined entirely by a tradeoff between the expected return on investment and the psychological costs of not investing. When $\alpha_{i} \rightarrow \infty$, the investor is extremely cooperative and will invest the entire endowment $(s=e)$. Higher values of $\alpha_{i}$ also mean the utility derived from the expected return on investment is greater.

The normalized utility function of the trustee $j$, assuming he has received a positive investment, is given by:

$$
W_{j}(s, r)=1-g\left(s, \beta_{j}\right) f\left(\frac{3 s-r}{3 s}\right)-f\left(\frac{r}{3 s}\right)
$$

As before, the function $f(x)=x^{2}$ represents the psychological cost of taking an action different from the boundary condition (i.e., keep everything or return everything). Likewise, trustees also bear guilt costs by keeping income from the tripled investment instead of "going along" with social assumptions of the typical trust-based contract (which proscribes trustworthy reciprocity). Additionally, the trustee bears insecurity costs by issuing returns: though social expectations may exist, there is uncertainty as to whether the regard for cooperation with the investor is appreciated, and whether any progress has been made towards developing a reliable 
trust-based exchange relationship. The relative differences in these costs is captured by the weight $g\left(s, \beta_{j}\right)$. As with the investor, the value depends upon the weight of the trustee's predisposition to cooperation $\beta_{j}$, where $\beta_{j} \geq 0$ is drawn from a distribution characterized by a distribution function $q(\beta)$. However, the value also depends on the investment amount $s$. When $g\left(s, \beta_{j}\right)=0$, the trustee is extremely selfish and will return nothing $(r=0)$. When $g\left(s, \beta_{j}\right) \rightarrow$ $\infty$, the trustee is extremely cooperative and will return the entire tripled amount to the investor $(r$ $=3 s$ ). The functional weight is modeled as:

$$
g\left(s, \beta_{j}\right)=\frac{1+h(s)}{1+\beta_{j}} \beta_{j}
$$

The function $h(s)$ represents the trustee's inference of the investor's type $\alpha$ and increases in s. Similar to Bacharach, Guerra and Zizzo, (2007) and Dufwenberg and Kirchsteiger (2004), reciprocity $g\left(s, \beta_{j}\right)$ increases with the amount invested $s$, as the weight placed upon psychological cost of keeping everything is weakly increasing in the inference of the investor's $\alpha$. When the inference $h(s)<\beta_{j}$ then $g\left(s, \beta_{j}\right) \leq \beta_{j}$, and when $h(s)>\beta_{j}$ then $g\left(s, \beta_{j}\right) \geq \beta_{j}$ (both relationships hold with inequality when $\beta_{j}>0$ ). The inference is modeled as:

$$
h(s)= \begin{cases}\alpha^{*} & \text { when } s=e \\ \alpha & \text { otherwise }\end{cases}
$$

The constant $\alpha^{*}$ is the trustee's conjectured infima $\alpha$ s.t. $s=e$, allowing for a pooling of investors. The truncation is motivated by research suggesting people prefer estimates based on the end of the continuum that best provides them justification for selfish behavior (Hsee, 1995; Schweitzer and Hsee, 2002; Shalvi et al., 2011).

Assuming the support of both $\alpha$ and $\beta$ are on the unit interval, when $0 \leq g\left(s, \beta_{j}\right) \leq 1$, the trustee will return a weakly positive amount, but no more than half the amount received. The amount returned is characterized by the first order condition: 


$$
r^{*}\left(s, \beta_{j}, \alpha^{*}\right) \equiv \operatorname{argmax}_{0 \leq r \leq 3 s} W_{j}(s, r)=\frac{3 \beta_{j} s(1+h(s))}{1+2 \beta_{j}+\beta_{j} h(s)}
$$

From (5), the return $r^{*}$ is increasing in $s, \beta_{j}$, and $\alpha^{*}$. The amount sent $s$ both changes the action space, as $0 \leq r \leq 3 s$, and inference of the investor's $\alpha$ via $h(s)$, both of which increase $r\left(s, \beta_{j}, \alpha^{*}\right)$, so the overall affect is quadratic. This implies that the return on investment (ROI), defined as $(s-r) / s$, is also increasing in $s$. This leads to the first hypothesis:

Hypothesis 1: Trustees are responsive to trust. Return and ROI are increasing in the amount of investment.

To characterize the infima $\alpha$ s.t. $s=e$ for the Continuous treatment, (i) insert the trustee's conjecture $\alpha^{*}$ in the return function (5), (ii) $\operatorname{set} \frac{\partial W_{i}(s)}{\partial s}=0$ and solve for $s$ temporary ignoring the boundary conditions, and (iii) set the expression equal to $e$, yielding:

$$
\int_{0}^{1} \frac{3 \beta e\left(1+\alpha^{*}\right)}{1+2 \beta+\beta \alpha^{*}} q(\beta) d \beta=\frac{2 e}{(1+\alpha)}
$$

Equation (6) can be rewritten as $(1+\alpha) \mathbb{E}\left(r^{*}\right)=2 e$, where $\mathbb{E}\left(r^{*}\right)$ is the expected return given the entire endowment is invested. When $\mathbb{E}\left(r^{*}\right)=2 e$ (the trustee returns on average twothirds the amount received), in which case all investors should invest the entire endowment. When $\mathbb{E}\left(r^{*}\right)<e$, then no investor should invest the endowment, but may invest something less than the endowment. For $e<\mathbb{E}\left(r^{*}\right)<2 e$, a proportion of investors pool and invest the entire endowment. In equilibrium the conjectured cutoff is correct, so the right hand side of equation (6) is $2 e /\left(1+\alpha^{*}\right)$ which is decreasing in $\alpha^{*}$. When the cutoff exists, it is unique as the left hand side of equation (6) is increasing in $\alpha^{*}$.

Let $\alpha^{B}$ denote the infima $\alpha$ s.t. $s=e$ for the Binary treatment. An investor will invest the entire endowment when $W_{i}(10)>W_{i}(0)$, and is indifferent when $W_{i}(10)=W_{i}(0)$, which yields: 


$$
\int_{0}^{1} \frac{3 \beta e\left(1+\alpha^{B}\right)}{1+2 \beta+\beta \alpha^{B}} q(\beta) d \beta=\frac{(1-\alpha) e}{(1+\alpha)}
$$

Equation (7) can be rewritten as $(1+\alpha) \mathbb{E}\left(r^{B}\right)=(1-\alpha) e$, where $\mathbb{E}\left(r^{B}\right)$ is the expected return in the Binary treatment given the entire endowment is invested. When $\mathbb{E}\left(r^{B}\right)>e$, then all investors should invest the entire endowment. However, even when $\mathbb{E}\left(r^{B}\right)<e$, some investors should invest the entire endowment. In equilibrium the conjectured cutoff is correct, so the right hand side of equation (7) is $\left(1-\alpha^{B}\right) e /\left(1+\alpha^{B}\right)$, and again the cutoff is unique. Since the right hand side of equation (6) is always greater than the right hand side of equation (7) for any given $\alpha$, and the cutoff is the point where the right hand side and the left hand side intersect, then the cutoff $\alpha^{*}>\alpha^{B}$. This leads to the second hypotheses.

Hypothesis 2: The proportion of $\$ 10$ investments in the Binary treatment is higher than in the Continuous treatment.

Because $r^{*}\left(s, \beta, \alpha^{*}\right)$ is increasing in the cutoff it follows that $r^{*}\left(s=e, \beta, \alpha^{*}\right) \geq$ $r^{B}\left(s=e, \beta, \alpha^{B}\right)$ for all $\beta$ (and with inequality for $\beta>0$ ). Therefore, conditional on investing the entire endowment $s=e$, the expected ROI is strictly greater in the Continuous treatment than in the Binary treatment, leading to the last hypothesis.

Hypothesis 3: Conditional on investment of \$10, the average ROI in the Binary treatment is lower than in the Continuous treatment.

\section{Results}

No significant differences were found between the sessions of a given treatment (seven for the Continuous treatment and four for the Binary treatment), so the combined results of sessions are reported. Figure 1 displays a bubble plot of the amount sent and returned in both treatments. There is substantial variability in individual behavior. On average, investors in the 
Continuous treatment invested $\$ 5.50(\mathrm{SEM}=0.43, N=76)$ and trustees returned $\$ 5.86(\mathrm{SEM}=$ $0.67)$, resulting in earnings of $\$ 10.35(\mathrm{SEM}=0.36)$ and $\$ 10.65(\mathrm{SEM}=0.76)$, respectively. These results are consistent with previous findings of Berg et al. (1995). In the Binary treatment, on average investors invested $\$ 7.71(\mathrm{SEM}=0.61, N=48)$ and trustees returned $\$ 7.73(\mathrm{SEM}=$ $0.95)$, resulting in earnings of $\$ 10.02(\mathrm{SEM}=0.73)$ and $\$ 15.40(\mathrm{SEM}=1.42)$, respectively.

Result 1: Consistent with Hypothesis 1, in the Continuous treatment ROI is increasing in the amount invested.

Support: Figure 1 illustrates that in the Continuous treatment investments of $\$ 6$ or less generated average returns smaller than the investment, yielding negative ROI. However, investments larger than $\$ 7$ on average generated positive ROI. A simple OLS regression, where the dependent variable is the investment and the independent variable is the ROI, confirms that the relationship is highly significant $(\beta=0.71, t(62)=7.91, p<0.001, N=64, F(1,62)=62.50$, Adj. $\left.R^{2}=0.494\right)$. A quadratic OLS regression, shown in Figure 1 , results in better fit $(N=76$, $\left.F(2,73)=154.19, \mathrm{Adj} . R^{2}=0.809, \mathrm{BIC}=369.58\right)$ than a linear model of investment $(N=76$, $F(1,74)=243.00$, Adj. $\left.R^{2}=0.767, \mathrm{BIC}=380.32\right)$. The increase in Adj. $R^{2}$ from 0.767 to 0.809 is significant $(F(1,73)=16.03, p<0.001)$.

Result 2: Consistent with Hypothesis 2, the proportion of $\$ 10$ investments in the Binary treatment is higher than in the Continuous treatment.

Support: In the Binary treatment $77 \%$ of investors invested \$10, while in the Continuous treatment only $28 \%$ did. Fisher's exact test indicates the difference is significant $\left(p<0.001, n_{1}=\right.$ $48, n_{2}=76$ ). The investment in the Binary treatment (MEDIAN $\left.=\$ 10.0\right)$ is significantly higher than in the Continuous treatment (MEDIAN $=\$ 5.5)$ based on the Mann-Whitney test $(Z=5.125$, $p<0.001)$. However, investor's earnings in the Binary treatment (MEDIAN $=\$ 10.0$ ) do not 
differ significantly from the Continuous treatment (MEDIAN $=\$ 10.0)$ based on the MannWhitney $(Z=1.193, p=0.23)$. The increase in wealth created by increased investment is captured by trustees who earned significantly more $(Z=5.059, p<0.001)$ in the Binary treatment $($ MEDIAN $=\$ 15.0)$ than in the Continuous treatment $($ MEDIAN $=\$ 12.62)$.

Result 3: Conditional on investment of $\$ 10$, the average ROI is lower in the Binary treatment than in the Continuous treatment.

Support: Conditional on investment of $\$ 10$, the average ROI was $0.00(\mathrm{SEM}=0.09, N=$ 37) in Binary treatment and 0.27 (SEM $=0.08, N=21)$ in the Continuous treatment. This difference is marginally significant based on the Mann-Whitney $(Z=1.647, p=0.091)$. Error! Reference source not found. illustrates the distribution of returns conditional on investment of $\$ 10$ by treatment. In the Binary treatment, $27 \%$ of trustees returned less than $\$ 10,24 \%$ returned exactly $\$ 10$, and $49 \%$ returned more than $\$ 10$. In contrast, in the Continuous treatment only 5\% of trustees returned less than $\$ 10,24 \%$ returned exactly $\$ 10$, and $71 \%$ returned more than $\$ 10$. The proportion of $\$ 10$ investments earning weakly positive ROI is significantly lower in the Binary treatment (73\%) than in the Continuous treatment (95\%) based on the Fisher's exact test $\left(p=0.04, n_{1}=37, n_{2}=21\right)$.

\section{Discussion and Conclusion}

The original study of Berg et al. (1995) documented that roughly half of investors invest $\$ 5$ or less out of $\$ 10$. Moreover, trustees tend to return an amount greater than invested to those who invested more than $\$ 5$, but return less than the amount invested to those who did not. Others, including Ben-Ner and Putterman (2009), Johnson and Mislin (2011), and Rietz et al. (2012), observed this pattern. In the Continuous treatment there is a significant relationship between the 
amount invested and the ROI. This is consistent with our conjecture that maximal investment in the Continuous treatment serves as a salient signal of maximal trust (encouraging trustee reciprocation) while maximal investment in the Binary treatment is not such a clear signal of maximal trust (trustee cannot confidently arrive at such a conclusion). Accordingly, our findings show that returns on maximal investments in the Binary treatment tend to be much lower than in the Continuous treatment. ${ }^{2}$

Our study provides clear evidence that the granularity of the investors' action space effects their demonstrable index of trust, in turn impacting reciprocity. While amounts invested appear to have signal value indexing trust, the binary "all or nothing" action space limits demonstrability of this trust index, obfuscating the trustee's perception. Although the coarser grained action space (limited to all or nothing alternatives) does lead to a higher average investment, resulting in greater welfare, it also appears to "backfire" for investors who do not share in the increased wealth as do investors of equal amounts from the Continuous treatment. Most studies measuring trust employ variants of either the continuous version of the trust game of Berg et al. (1995) or the binary version of the trust game of Güth et al. (1997). Although the binary game may be more appealing to implement due to the convenience of procedural simplification and enhanced statistical power, the two games, as we find, produce disparate

\footnotetext{
${ }^{2}$ An alternative explanation is that trustees simply decide how much to reciprocate by comparing investments received to a prior reference point. A number of experiments have documented that participants on average have correct expectations about the behavior of others (Dufwenberg and Gneezy, 2000; Guerra and Zizzo, 2004; Bacharach et al., 2007; Casari and Cason, 2009; Bellemare et al., 2010). Conditional on correct expectations, trustees who received an investment of $\$ 10$ in the Continuous treatment may have compared this to the average investment of $\$ 5.50$, considered it a comparatively large investment and thus reciprocate a relatively greater amount, while trustees who received the investment of $\$ 10$ in the Binary treatment and compared it to the average investment of $\$ 7.71$ were not as impressed by the comparison and so reciprocated relatively less. Evaluating the possibility of this explanation, we noted that the data does not provide empirical support. When examining investments between $\$ 7$ and $\$ 8$ in the Continuous treatment (i.e., a similar difference from the average as between maximal and average investments in the Binary treatment), the ROI is marginally greater (MEDIAN $=0.45$ ) than in the Binary treatment $($ MEDIAN $=0.00)$ based on the Mann-Whitney test $\left(Z=1.710, p=0.087, n_{1}=26, n_{2}=37\right)$.
} 
behavior. There is a convention among some researchers of referring to the Berg et al. (1995) procedure as the "investment game" and the Güth et al. (1997) procedure as the "trust game". Indeed, there are many early examples of often-cited studies (Snijders, 1996; Camerer \& Weigelt, 1988, Dasgupta 1988; Kreps, 1990), as well as more recent studies (Malhotra \& Murnighan, 2002; Schniter, Sheremeta \& Sznycer, 2013), referring to games with binary choices as "trust games". ${ }^{3}$ While all the aforementioned research furthers understanding of behavior, the results of this manuscript suggest caution be taken when extending results from one game to the other. Furthermore, while the fundamental kinds of determinates motivating trust and reciprocity in binary trust games should correspond to determinates of trust and reciprocity observed in continuous games, the degree to which these determinates actually motivate trust and reciprocity should depend on the granularity of the action space useful for signaling the calibration of internal motivations.

Finally, we conclude that it is ironic that the procedure better suited for eliciting the relationship between trust and trustworthiness is often called the "investment game", while the game that is not as well suited is usually called the "trust game." Although the binary "trust game" may be more appealing to implement due to the convenience of procedural simplification and enhanced statistical power, we suggest that the Berg et al. (1995) continuous "investment game" is be better suited for investigating the relationship between demonstrable trust and trustworthiness.

\footnotetext{
${ }^{3}$ However, the convention of referring to the continuous game as the "investment game" and the binary game as the "trust game" is not widely adopted. For example, Johnson and Mislin (2011) report the results from 162 replications of Berg et al. (1995) in a meta-analysis, labeling the replications "trust games" and excluding games where the participants made binary choices.
} 


\section{Acknowledgements}

We thank Daniel Balliet, Cary Deck, Martin Dufwenberg, Joaquín Gómez-Miñambres, Salar Jahedi, Daniel Sznycer, and seminar participants at the 2013 ESA World Meeting in Zurich

for helpful feedback. We are grateful to Chapman University and the Economic Science Institute for research support. 


\section{References}

Andreoni, J., \& Petrie, R. (2004). Public goods experiments without confidentiality: a glimpse into fund-raising. Journal of Public Economics, 88, 1605-1623.

Bacharach, M., Guerra, G., \& Zizzo, D.J. (2007). The self-fulfilling property of trust: An experimental study. Theory and Decision, 63, 349-388.

Bellemare, C., Kröger, S., \& Bissonnette, L. (2010). Bounding Preference Parameters under Different Assumptions about Beliefs: a Partial Identification Approach. Experimental Economics, 13, 334-345.

Ben-Ner, A., \& Putterman, L. (2009). Trust, communication and contracts: An experiment. Journal of Economic Behavior and Organization, 70, 106-121.

Berg, J., Dickhaut, J., \& McCabe, K. (1995). Trust, Reciprocity, and Social History. Games and Economic Behavior, 10, 122-142.

Camerer, C., \& Weigelt, K. (1988). Experimental tests of a sequential reputation model. Econometrica, 56, 1-36.

Casari, M., \& Cason, T.N. (2009). The strategy method lowers measured trustworthy behavior. Economics Letters, 103, 157-159.

Dasgupta, P. (1988). Trust as a Commodity. In Gambetta, D. (Ed.), Trust: Making And Breaking Cooperative Relations. Cambridge: Blackwell.

Dufwenberg, M., \& Gneezy, U. (2000). Measuring Beliefs in an Experimental Lost Wallet Game. Games and Economic Behavior, 30, 163-182.

Dufwenberg, M., \& Kirchsteiger, G. (2004). A theory of sequential reciprocity. Games and Economic Behavior, 47, 268-298.

Eckel, C.C., \& Wilson, R.K. (2004). Is Trust a Risky Decision? Journal of Economic Behavior and Organization, 55, 447-465.

Falk, A., \& Gächter, S. (2002). Reputation and reciprocity - consequences for the labour relation. Scandinavian Journal of Economics, 104, 1-26.

Fehr, E., Gächter, S., \& Kirchsteiger, G. (1996). Reciprocal fairness and noncompensating wage differentials. Journal of Institutional and Theoretical Economics, 152, 608-640.

Gómez-Miñambres, J. \& Schniter, E. (2013) Menu-Dependent Emotions and Self-Control Chapman University working paper, dx.doi.org/10.2139/ssrn.2152036, 1-34.

Güth, W., Ockenfels, P., \& Wendel, M. (1997). Cooperation based on trust. An experimental investigation. Journal of Economic Psychology, 18, 15-43.

Hotelling, H. (1929). Stability in Competition. Economic Journal, 39, 41-57.

Hsee, C.K. (1995). Elastic justification: How tempting but task irrelevant factors influence decisions. Organizational Behavior and Human Decision Processes, 62, 330-337.

Johnson, N.D., \& Mislin, A.A. (2011). Trust Games: A Meta-analysis. Journal of Economic Psychology, 32, 865-889.

Kreps, D. M. (1990). Corporate culture and economic theory. In J. Alt \& K. Shepsle (Eds.), Perspectives on positive political economy. New York: Cambridge University Press.

Malhotra, D., \& Murnighan, K. (2002). The Effects of Contracts on Interpersonal Trust. Administrative Science Quarterly, 47, 534-559.

Ostrom, E. \& Walker, J. (2003). Trust and Reciprocity: Interdisciplinary Lessons from Experimental Research. New York: Russell Sage Foundation Publications.

Reuben, E., Sapienza, P. \& Zingales, L. (2009). Is Mistrust Self-Fulfilling? Economics Letters 104, 89-91. 
Rietz, T., Schniter, E., Sheremeta, R.M., \& Shields, T.W. (2012). Trust, reciprocity, and rules. Chapman University, Working Paper.

Schniter, E., Sheremeta, R.M., \& Sznycer, D. (2013). Building and rebuilding trust with promises and apologies. Journal of Economic Behavior and Organization, forthcoming.

Schweitzer, M. E., \& Hsee, C. K. (2002). Stretching the truth: Elastic justification and motivated communication of uncertain information. Journal of Risk and Uncertainty, 25, 185-201.

Shalvi, S., Dana, J., Handgraaf, M.J., \& De Dreu, C.K. (2011). Justified ethicality: Observing desired counterfactuals modifies ethical perceptions and behavior. Organizational Behavior and Human Decision Processes, 115, 181-190.

Snijders, C. (1996). Trust and commitments. Interuniversity Center for Social Science Theory and Methodology, Purdue University Press. 
Figure 1: Bubble Plots of Investment and Return in Continuous and Binary Treatments

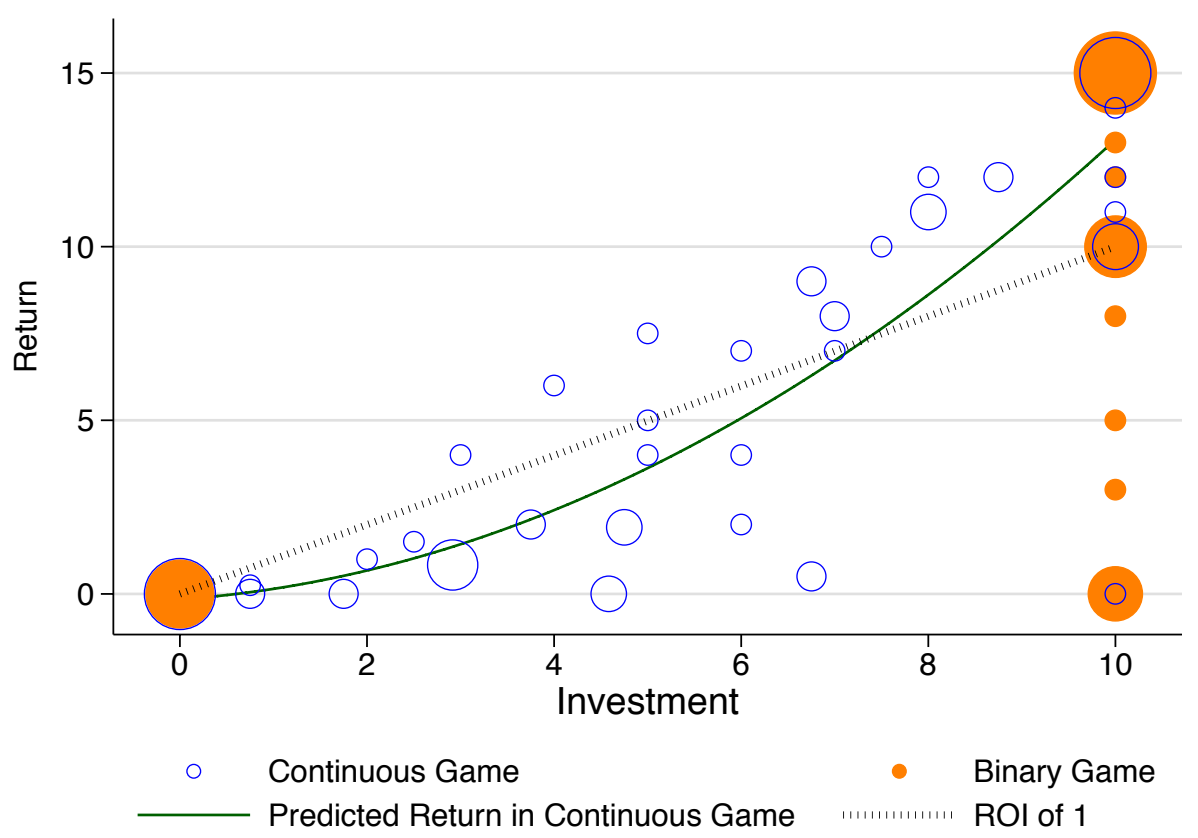

Note: Observations are plotted with bubbles, where the relative size indicates the proportion of observations in the treatment. The smallest bubble plotted represents approximately 1.5 percent and the largest bubble plotted approximately 33 percent.

Figure 2: Distribution of Returns Conditional on Investment of \$10 by Treatment

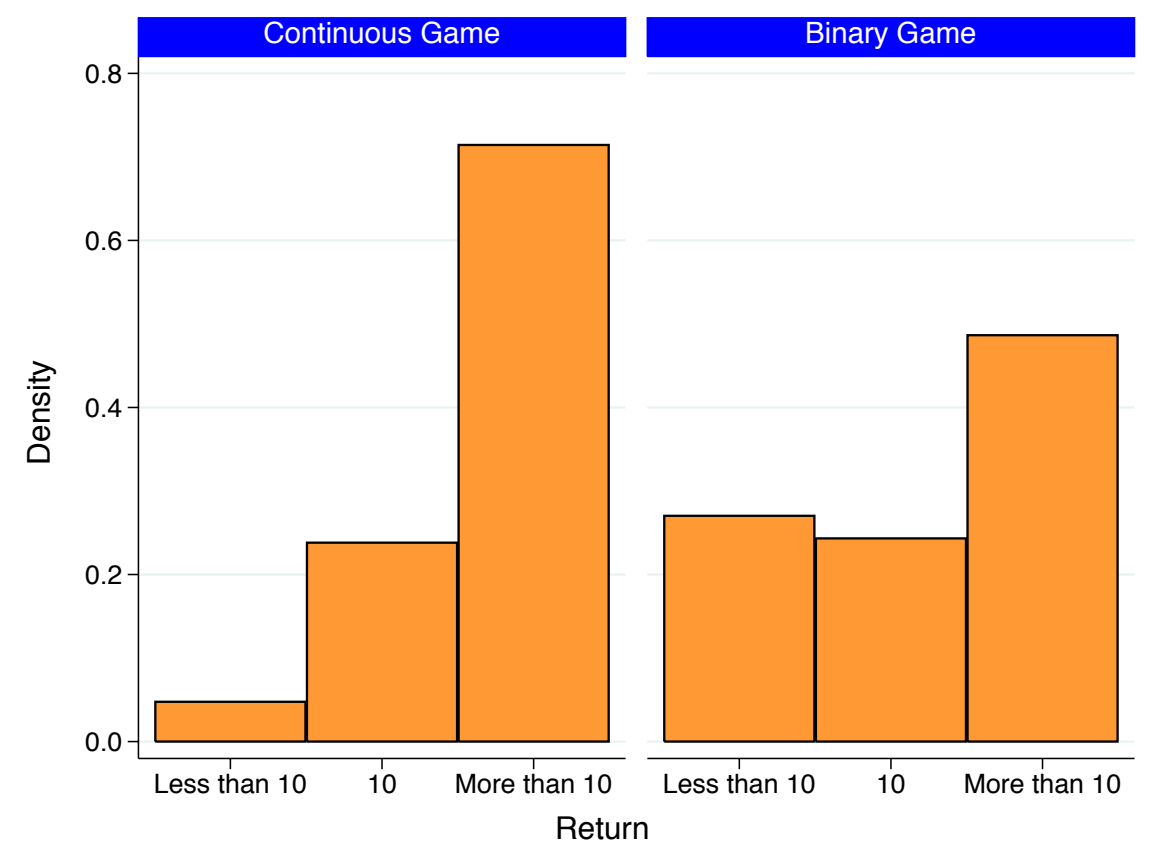




\section{Appendix (Not For Publication) - Instructions for the Continuous Treatment}

\section{INSTRUCTIONS}

This is an experiment in the economics of decision-making. Various research agencies have provided funds for this research. The currency used in the experiment is experimental dollars, and they will be converted to U.S. Dollars at a rate of _1_ experimental dollars to _1 dollar. At the end of the experiment your earnings will be paid to you in private and in cash. It is very important that you remain silent and do not look at other people's work. If you have any questions, or need assistance of any kind, please raise your hand and an experimenter will come to you. If you talk, laugh, exclaim out loud, etc... you will be asked to leave and you will not be paid. We expect, and appreciate, you adhering to these policies.

The participants in today's experiment will be randomly assigned into two-person groups. In addition to the group assignment each participant will also be randomly assigned to a specific type in the group, designated as Person 1 or Person 2. You and the other participant in your group will make choices that will determine your payoffs. The experiment consists of two decision stages.

In stage 1, Person 1 receives $\$ 10$ and then decides how many dollars to send to Person 2. Person 1 can send none, more than none, or all of the $\$ 10$ to Person 2 . The amount sent by Person 1 is tripled before reaching Person 2. In stage 2, Person 2 decides how many of the dollars they received to send back to Person 1. Person 2 can send back none, more than none, or all of the amount received back to Person 1. At that point the experiment is over.

Next we describe in details the decisions made by both persons in each stage of the experiment.

Stage 1: Person 1 receives $\$ 10$ and then decides how many dollars to send to Person 2. Person 1 can send none, more than none, or all of the $\$ 10$. Person 1 enters the amount sent to Person 2 in the box labeled "The amount sent by Person 1" below. Person 1 keeps any amount that is not sent to Person 2. The amount sent by Person 1 is tripled before reaching Person 2.

Person 1 can send none, more than none, or all of $\$ 10$ to Person 2.

Person 2 can send back $20 \%$, more than $20 \%$, or all of the multiplied amount received from Person 1

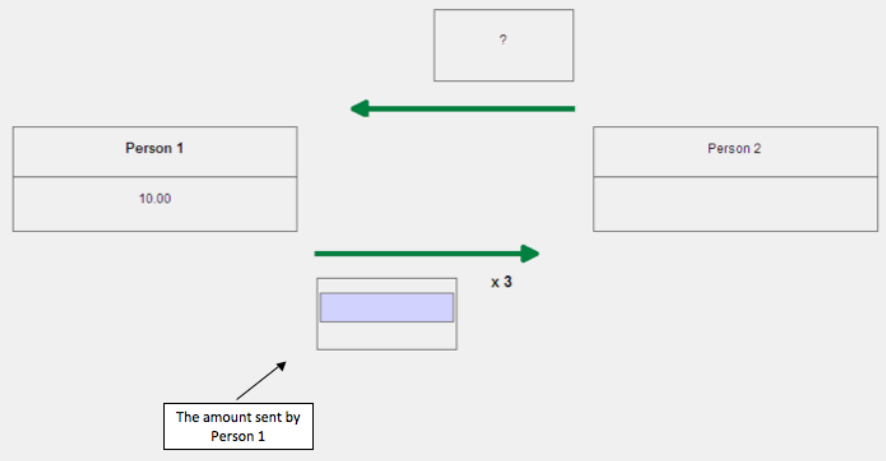

Decision Screen for Person 1 in Stage 1 
Stage 2: After learning the amount sent by Person 1, Person 2 decides how many dollars to send back to Person 1. Person 2 can send back none, more than none, or all of the amount in Person 2's account at that time. Person 2 enters the amount sent back to Person 1 in the box labeled "The amount sent back by Person 2" below. The amount sent back by Person 2 is NOT multiplied. Person 2 keeps any amount that is not sent back to Person 1.

Person 1 can send none, more than none, or all of $\$ 10$ to Person 2

Person 2 can send back 20\%, more than 20\%, or all of the multipled amount received from Person

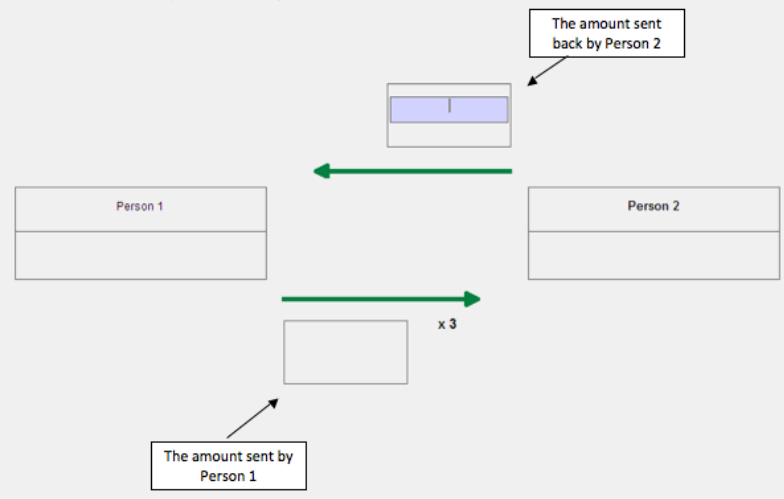

Decision Screen for Person 2 in Stage 2

Finally, at the end of the Stage 2 the total earnings are reported to each person. Person 1's earnings will equal \$10 less the amount sent to Person 2 plus the amount sent back by Person 2 . Person 2's earning will equal three times the amount sent by Person 1 less the amount sent back to Person 1.Please record the decisions and your earnings on your record sheet under the appropriate heading.

\section{SUMMARY}

The computer will assign you and one other participant to a two-person group, consisting of Person 1 and Person 2. In stage 1, Person 1 receives $\$ 10$ and then decides how many dollars to send to Person 2. Person 1 can send none, more than none, or all of the $\$ 10$. The amount sent by Person 1 is tripled. In stage 2, Person 2 decides how many dollars to send back to Person 1 . Person 2 can send back none, more than none, or all of the amount in Person 2's account at that time. At the end of Stage 2 the total earnings are reported to each person. This experiment is now over and your earnings will be part of the total you will be paid. 